\title{
Heparin-Coated Liposomes Improve Antiplasmodial Activity and Reduce the Toxicity of Poupartone B
}

\section{(ㄷ) (i) (우 $\Theta$}

\author{
Authors \\ Allison Ledoux ${ }^{1}$, Lucia Mamede ${ }^{1}$, Claudio Palazzo ${ }^{2}$, Tania Furst ${ }^{2}$, Olivia Jansen ${ }^{1}$, Pascal De Tullio $^{3}$, Védaste Kagisha1, \\ Hélène Pendeville ${ }^{4}$, Marianne Fillet ${ }^{5}$, Géraldine Piel ${ }^{2}$, Michel Frédérich ${ }^{1}$
}

\section{Affiliations}

1 Laboratory of Pharmacognosy, Center of Interdisciplinary Research on Medicines, CIRM, University of Liège, Liège, Belgium

2 Laboratory of Pharmaceutical Technology and Biopharmacy, Center of Interdisciplinary Research on Medicines, CIRM, University of Liège, Liège, Belgium

3 Laboratory of Pharmaceutical Chemistry, Center of Interdisciplinary Research on Medicines, CIRM, University of Liège, Liège, Belgium

4 Plateforme Zebrafish Facility and Transgenics, GIGA, University of Liège, Liège, Belgium

5 Laboratory for the Analysis of Medicines, Center of Interdisciplinary Research on Medicines, CIRM, University of Liège, Liège, Belgium

Key words

poupartone, liposome, malaria, artemisinin resistance, Poupartia borbonica, anacardiaceae

$\begin{array}{ll}\text { received } & 04.11 .2019 \\ \text { revised } & 01.04 .2020 \\ \text { accepted } & 13.04 .2020\end{array}$

Bibliography

DOI https://doi.org/10.1055/a-1158-0569

Planta Med Int Open 2020; 7: e73-e80

(c) Georg Thieme Verlag KG Stuttgart · New York

ISSN 2509-9264

\section{Correspondence}

Allison Ledoux

Laboratory of Pharmacognosy, Center of Interdisciplinary Research on Medicines, CIRM University of Liège Avenue Hippocrate 15

4000 Liège

Belgium

Tel.: + 32436646 38, Fax: + 3243664332

allison.ledoux@uliege.be

\section{ABSTRACT}

Poupartone $B$ is an alkyl cyclohexenone derivative isolated from Poupartia borbonica. This compound demonstrated promising antimalarial activity $\left(\mathrm{IC}_{50}<1 \mu \mathrm{g} / \mathrm{mL}\right)$, however, it was not devoid of toxicity. Thus, to reduce the adverse side effects of this natural bioactive molecule, a delivery strategy involving a nanostructure was formulated. Additionally, poupartone B-loaded liposomes were coated with heparin, a glycosaminoglycan that is known to target proteins on the surface of Plasmodium falciparum-infected red blood cells. The quantification of the compound in the formulation was performed by HPLC-DAD, while heparin was quantitated by ${ }^{1} \mathrm{H}$ NMR spectroscopy. The liposomes' antiplasmodial activity was tested on artemisininresistant $P$. falciparum isolate, and toxicity was evaluated on human HeLa cells and zebrafish embryos. Throughout this research, the formulation demonstrated higher antiplasmodial activities against both $P$. falciparum strains and a significant decrease of in vitro toxicity. The formulation improved the selectivity index 2 times in vitro and proved to be 3 times less toxic than the compound alone in the zebrafish embryo acute toxicity test. Hence, the use of this strategy to deliver natural products in Plasmodium-infected cells, particularly those with a narrow therapeutic margin, is proposed.

\section{Introduction}

Malaria is caused by a parasitic protozoan transmitted by Anopheles sp. mosquitos. The pathology's symptoms in the human host are caused by a particular life stage of the parasite, the erythrocytic stage, that involves the invasion and destruction of infected red blood cells (iRBCs). This process causes fever, chills, and anemia and can lead to severe symptoms, as in the case of cerebral malaria, such as coma and seizures, leading to the death of the patient. This pathology still urgently needs scientific investigation due to the resistance of parasites to available medicines. Indeed, the emer- 
gence of artemisinin-resistant strains is a threat to eradication policies and reminds the community of the development of chloroquine resistance that happened in the 1960s in Asia [1], and which has since then spread to Africa, making the use of the compound more and more difficult.

According to the last World Malaria Report published by the World Health Organization (WHO), an estimated 216 million cases of malaria occurred in 2016, while 211 million cases were reported in 2015. This pathology is evidence of a high burden, having killed 438000 people in 2015 and 445000 in 2016, mostly children under 5 years. For the first time in the last 10 years, a substantial increase in incidence rates occurred worldwide, of which around $99 \%$ of the cases can be attributed to Plasmodium falciparum[2]. According to the $\mathrm{WHO}$, the emergence of parasite resistance to antimalarial medicines and the lack of a sustainable and predictable international and domestic funding are involved in the upsurge of malaria.

Artemisinin-based combination therapies have contributed to lower mortality rates, but, unfortunately, decreased clinical efficacy of artemisinin derivatives has already been reported in Southeast Asia [3]. Due to the ability of the mutated parasite to employ a quiescence mechanism, it is able to survive the short exposition time to dihydroartemisinin (DHA), the active metabolite of artemisinin, which has a short half-life, resulting in a slower rate of parasite clearance and recrudescence in patients [4].

Natural products have an incalculable therapeutic potential for antimalarial drug discovery. The source of many currently used drugs is inspired or directly derived from nature [5]. Poupartones are alkyl cyclohexenones derivatives isolated from the leaves of Poupartia borbonica Gmel. Previous studies showed the antimalarial potential of this kind of compound. Poupartones are highly active against $P$. falciparum, and previous in vivo studies on mice showed a growth inhibition of $69.5 \%$ at day 7 post-infection at 15 $\mathrm{mg} / \mathrm{kg} /$ day [6]. Unfortunately, even if the mice treated showed a decrease in parasitemia, they died prematurely. A preliminary testing on zebrafish larva demonstrated high contact toxicity as well as hints of cardiac toxicity, observed by a binocular microscope. For such compounds with promising activity, but potential toxicity, new drug delivery systems have to be developed with two main priorities: (1) to eliminate the parasite with maximum specificity and (2) to lower the adverse side effects of the drug compound.

iRBCs can be an interesting target for a controlled delivery system. In fact, iRBCs are known to express proteins on their surface that are not expressed in non-infected RBCs, thus presenting themselves as targets. These protein complexes, called knobs, are present in iRBC surfaces and allow effective cytoadhesion. This phenomenon is important for the parasite's survival, because it prevents elimination by splenic clearance. iRBC sequestration appears after 16-20 h post-invasion, when iRBCs are able to display these adhesive properties. Because iRBCs are sequestered in different organs, such as the brain and the lung, it leads to multiple problems, including hypoxia, hypoglycemia, and microvascular dysfunctions resulting in severe malaria, as mentioned previously [7]. The knob contains different proteins, including $P$. falciparum erythrocyte membrane 1 (PfEMP1) proteins, responsible for the adhesion phenomenon resulting in the rosetting of iRBCs [8].

Glycosaminoglycans, like heparin, are able to inhibit PfEMP1 proteins and, in this way, could prevent rosetting. Furthermore, its ability to bind this specific erythrocyte membrane protein constitutes a good opportunity for the targeting strategy of nanocarriers $[9,10]$. Heparin is also able to bind parasite proteins, such as the circumsporozoite (CS) protein. The CS protein is present on the sporozoites' and merozoites' cell surface and plays a role in hepatocyte invasion [11]. This approach represents a two-in-one opportunity to improve the efficiency of a targeting approach strategy, which was exploited with success by Marques et al. [10] in the development of liposomes loaded with chloroquine and coated with heparin.

Liposomes are small vesicles made of concentric spheres of lipids. They are biocompatible and allow for the controlled release of both hydrophilic and hydrophobic drugs. Compared to other nanoparticle systems, they demonstrated better capability to enhance the selectivity index of drugs by prolonging systemic circulation time and minimizing toxicity and immunogenicity [12]. In vivo assays performed with liposomes of artemisinin demonstrated a much longer blood circulation time than free artemisinin [13], hence demonstrating a good strategy for the development of therapeutics to treat parasitic diseases. Because this approach is very advantageous, several liposome formulations have been developed for malaria treatment, such as enclosing curcuminoids, chloroquine, and artemisinin derivatives, among others, which are described in the review of Aditya et al. [14].

Consequently, this strategy was applied to poupartone $B$, which revealed high antiplasmodial activity, but also toxicity, in previous studies [15]. This compound was selected because of the high bioactive potential of this class of compounds, which can be demonstrated further through nanocarrier technology. Indeed, the alkyl cyclohexanone derivatives isolated from some Anacardiaceae, such as Lannea rivae, Lannea welwitshii, Lannea edulis, Taparira guianensis, Taparira obtuse, and, more recently, from the mushroom Hygrophorus abieticola, demonstrated antimalarial, antibacterial, fungicidal, and anticancer activities [15-19]. The aim of this study was to demonstrate the applicability of this formulation in the delivery of an isolated natural compound while minimizing its toxicity and improving its selectivity index, even on a partially artemisinin-resistant strain.

\section{Results and Discussion}

Liposome formulations combined with poupartone $B$ ( $1.0 \mathrm{mg}$ for $20.0 \mathrm{mM}$ lipids) and $100 \mathrm{\mu g} / \mathrm{mL}$ heparin presented the most interesting parameters in terms of size, charge, and polydispersity index (PDI). The liposome size was $183 \pm 22 \mathrm{~nm}$ and $256 \pm 20 \mathrm{~nm}$ before and after heparin addition, respectively, LSA revealing a size augmentation due to the heparin attachment. The PDI was lower than 0.1 and, as a result, suitable for medical use [20]. The zeta potential was $16.6 \pm 1.7 \mathrm{mV}$ before the addition of heparin and decreased to $11.8 \pm 1.4 \mathrm{mV}$ after heparin electrostatic bonding. The fact that the charge remained positive, making this a cationic liposome, is an advantage, because these are preferably endocytosed by targeted cells as they are more attracted by the negatively charged cell membrane, improving the cellular concentration of the molecule of interest [20,21].

The pre-validation of the analytical procedure allows for verifying the method's ability to accurately quantify poupartone B in the 
liposome formulation. Linearity, trueness, precision, accuracy, limit of detection (LOD), and limit of quantification (LOQ) [22] were evaluated and are presented in $>$ Table 1.

The accuracy acceptance limits were set at $15 \%$, as per usual for isolated natural compounds. The upper and lower $\beta$-expectation tolerance limits never exceeded the acceptance limits ( $\vee$ Fig. 1). Considering these results, the HPLC method was found to fulfill its objective, that is the accurate quantification of poupartone $B$ in the liposomal matrix.

Liposomes were diluted ten times before injection in HPLC. Using a calibration curve, the formulation was found to contain $304 \pm 3 \mu \mathrm{g} / \mathrm{mL}(797.46 \pm 8 \mu \mathrm{M})$ of poupartone B in the $20 \mathrm{mM}$ of liposomes. The high activity of the compound allows for the use of a low concentration of product.

\section{Heparin quantification}

The quantification of heparin on the liposomes surface was performed indirectly, since the quantity incorporated was below the detection limit of several tested techniques. The alcian blue method [23] was tested, but it was not sensitive enough to obtain repeatable results. Hence, the method used was ${ }^{1} \mathrm{H}$ NMR performed on the lyophilized supernatants, which contained the heparin that was not incorporated in the liposome formulation. Maleic acid solution $5 \mathrm{mM}$ in $\mathrm{D}_{2} \mathrm{O}$ was used as a reference. The signal around 1.9 ppm is the proton signal from the acetyl group of the sugars in the heparin molecule. Through the integration of the maleic acid and the control of heparin, the average percentage of heparin was $25.78 \pm 0.63 \%$. This corresponds to $25.78 \mu \mathrm{g}$ of heparin on the liposomes surfaces ( $20 \mathrm{mM}$ total lipids, $0.80 \mathrm{mM}$ poupartone $B$ ) dispersed in $1.0 \mathrm{~mL}$ of PBS. Considering the $\mathrm{IC}_{50}$ of poupartone $\mathrm{B}(1.81 \mu \mathrm{M})$ [15], this quantity is thought to be adequate, as it stays within the interval of concentrations used by Marques et al. for targeting activities [10].

The formulation with poupartone $B$ and heparin tends to be more active than the free poupartone $B$, both on the chloroquinesensitive strain $3 \mathrm{D} 7$ as on the artemisinin partially resistant strain IPC 3445 ( $\triangleright$ Table 2).

This trend suggests liposome intracellular delivery of poupartone $B$ to the iRBCs and that the improvement is due to the heparin. The decrease of toxicity on nonvascular human HeLa cells, which were used previously to highlight the toxicity of poupartone's compounds [15], reinforces the idea that this improvement of activity only occurred on iRBCs, and thus confirmed the applicability of heparin as a targeting ligand to iRBCs. These elements together are encouraging, increasing the selectivity index from two times (on IPC strain) to three times (on 3D7 strain) for the poupartone $\mathrm{B} /$ heparin liposome formulation. The formulation could be a good solution to avoid the compounds inherent toxicity.

Prolonged parasite clearance times with artemisinin derivatives were reported in Southeast Asia, suggesting the presence of an artemisinin resistance phenotype [3]. It was observed that the ringstage parasites were able to develop a quiescent state, which was associated with a mutation in the Kelch 13 propeller domain [3]. In reality, the use of conventional in vitro methods to evaluate the $\mathrm{IC}_{50}$ of drugs cannot discriminate an artemisinin partially resistant strain from a susceptible one after exposure to DHA, the active metabolite [24]. In order to correlate survival of parasites in vitro with the
- Table 1 Pre-validation results ( $\mathrm{k}=$ number of series; $\mathrm{n}=$ number of replicates per series).

\begin{tabular}{|l|l|l|}
\hline $\begin{array}{l}\text { Trueness }(\boldsymbol{\mu g} / \mathbf{m L}) \\
(\mathbf{k}=\mathbf{2}, \mathbf{n}=\mathbf{3})\end{array}$ & Relative bias (\%) & \\
\hline 20 & -2.69 & \\
\hline 50 & -1.73 & \\
\hline 100 & -0.32 & \\
\hline Linearity & & \\
\hline Slope & $1.502 ; 1.513$ & \\
\hline Intercept & $-2.946 ;-4.131$ & Intermediate \\
\hline$r^{2}$ & $0.9920 ; 0.9994$ & 2.4 \\
\hline Precision & Repeatability RSD (\%) & 1.9 \\
\hline 20 & 1.7 & 0.7 \\
\hline 50 & 1.7 & \\
\hline 100 & 0.7 & \\
\hline LOQ $(\mu \mathrm{g} / \mathrm{mL})$ & 20 & \\
\hline LOD $(\mu \mathrm{g} / \mathrm{mL})$ & 5.3 & RSD (\%) \\
\hline
\end{tabular}

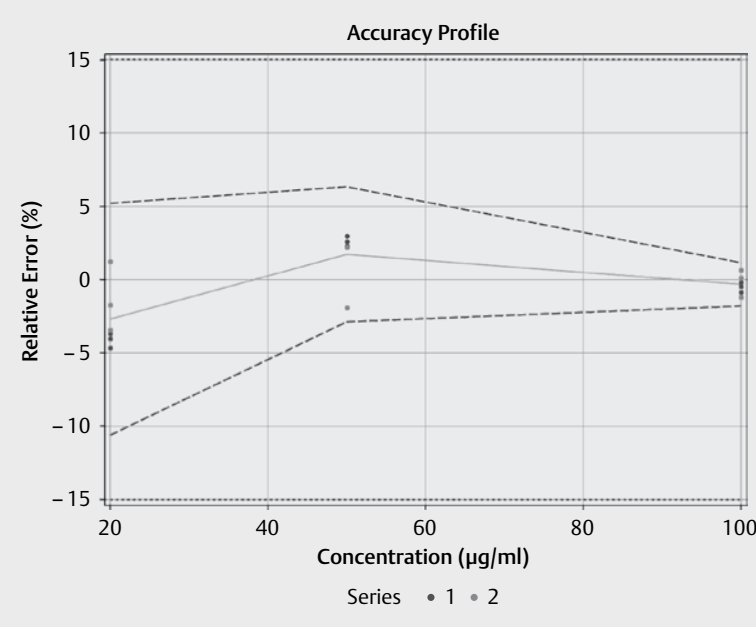

- Fig 1 Accuracy profile obtained considering a linear regression for poupartone $B$; plain line: relative bias, dashed lines: $\beta$-expectation tolerance limits, dotted lines: acceptance limits, and dots: relative back-calculated concentrations.

time of parasitic clearance observable in vivo, the ring-stage survival assay [25] was used where a short pulse of DHA treatment during the early ring stage of the erythrocyte phase allows for observing differences in susceptibility between the sensitive and resistant strain [25]. Synchronized young ring parasites were exposed to drugs during $6 \mathrm{~h}$ in correlation to the DHA's half-life. After the washing step, they were grown in medium for $66 \mathrm{~h}$ to evaluate recrudescence. The parasitic growth was assessed by microscopic analysis. The rate of parasite survival exposed to DHA, poupartone B, and the formulation containing poupartone $B$ with heparin is shown in $>$ Fig. 2.

Poupartone $B$ and the formulation were tested at the same concentration, corresponding to the $\mathrm{IC}_{50}$ of poupartone $\mathrm{B}$, as estab- 
- Table 2 Antiplasmodial and cytotoxic activities of poupartone B, empty liposomes, and liposomes containing poupartone B with or without heparin.

\begin{tabular}{|c|c|c|c|c|}
\hline Samples & $\begin{array}{l}\text { P. falciparum IC } 50(\mu \mathrm{g} / \mathrm{mL}) \\
(\mathrm{n}=3) 3 \mathrm{D} 7 \mathrm{IPC} 3445\end{array}$ & $\begin{array}{l}\text { Cytotoxicity } \mathrm{IC}_{50} \\
(\mu \mathrm{g} / \mathrm{mL})(\mathrm{n}=2) \text { HeLa }\end{array}$ & $\begin{array}{l}\text { Selectivity index } \\
\text { HeLa/3D7 HeLa/IPC } 3445\end{array}$ & Hemolysis (\%) \\
\hline Poupartone B & $\begin{array}{l}0.69 \pm 0.20 \\
0.40 \pm 0.15\end{array}$ & $1.44 \pm 0.34$ & $\begin{array}{l}2.09 \\
3.60 \\
\end{array}$ & $<1 \%$ \\
\hline Formulation without poupartone B & $\begin{array}{l}\text { NA } \\
\text { NA }\end{array}$ & NA & NA & $<1 \%$ \\
\hline $\begin{array}{l}\text { Formulation poupartone B- liposome without } \\
\text { heparin addition }\end{array}$ & $\begin{array}{l}0.86 \pm 0.26 \\
0.61 \pm 0.19\end{array}$ & $3.88 \pm 0.60^{* *}$ & $\begin{array}{l}4.51 \\
6.36 \\
\end{array}$ & $<1 \%$ \\
\hline $\begin{array}{l}\text { Formulation poupartone B- liposome added } \\
\text { with } 1.3 \mu \mathrm{g} \text { heparin/mM liposome lipids }\end{array}$ & $\begin{array}{l}0.41 \pm 0.01^{*} \\
0.35 \pm 0.08\end{array}$ & $2.52 \pm 0.02^{* *}$ & $\begin{array}{l}6.15 \\
7.20\end{array}$ & $<1 \%$ \\
\hline Artemisinin & $0.004 \pm 0.001$ & NT & - & NT \\
\hline Doxorubicin & NT & $0.085 \pm 0.055$ & - & NT \\
\hline
\end{tabular}

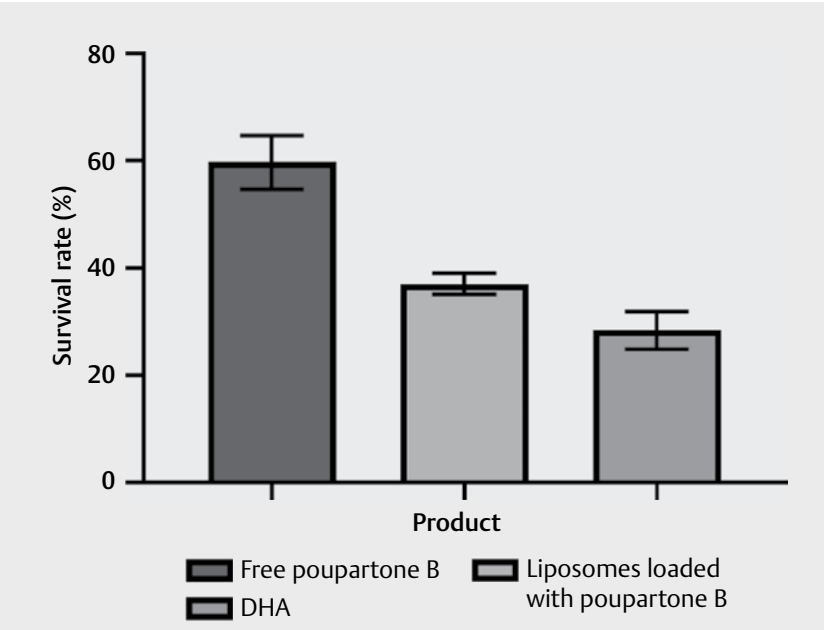

- Fig. 2 Survival rate of parasites in the RSA test (\%) with a treatment dose of $2.6 \mu \mathrm{M}$ poupartone $B$ and liposomes containing $2.6 \mu \mathrm{M}$ poupartone $B$ with heparin. DHA (700 nM) was used as a control.

lished by a conventional method, of $1 \mu \mathrm{g} / \mathrm{mL}(2.6 \mu \mathrm{M})$. This way, approximately half of the parasite's population survives, and the test is able to establish the difference of survivability of the Plasmodium artemisinin partially resistant strain between the free poupartone $B$ and the formulation.

The formulation showed an approximately 1.6-fold increase in potency compared to poupartone B alone, supporting the fact that the liposome's formulation is able to improve the activity by concentrating poupartone $B$ in red blood cells rapidly. As a whole, these results encourage further investigation, considering the liposomal system is able to deliver the compound in a short pulse time $(<6 \mathrm{~h})$. DHA was used as a control, and confirmed the partial resistance of the strain, as the survival rate was evaluated at $28 \pm 3.5 \%$.

The zebrafish embryo acute toxicity test was used to observe the reduction of toxicity obtained by the nanovectorization. Zebrafish embryo and larvae are easily obtained in high quantities, and the transparency of the embryos and the possibility to use the mutant's fluorescent embryos are convenient for investigating the causes of toxicity. Even if this model cannot replace rodents, it is very useful to qualitatively compare the toxicity of drugs in the early stages of research. Poupartone B and the liposome formulation were tested, and the petri dishes were observed at 24,48 , and $72 \mathrm{~h}$ post-fertilization ( $\vee$ Fig. 3 ), after the first treatment administration. At the $24 \mathrm{~h}$ mark, both populations were alive.

The survival rate at 10 and $5 \mu \mathrm{g} / \mathrm{mL}$ exposure concentrations differ greatly between the poupartone $B$ and the formulation. With $5 \mu \mathrm{g} / \mathrm{mL}$ poupartone $B$, half of the larvae were dead at $72 \mathrm{~h}$, which accounts for an $\mathrm{LC}_{50}$ of $5 \mu \mathrm{g} / \mathrm{mL}$. With $10 \mu \mathrm{g} / \mathrm{mL}$ the liposome's formulation, only 2 larvae died, thus the $\mathrm{LC}_{50}$ was set between 10 and $15 \mu \mathrm{g} / \mathrm{mL}$. At the end of the test, with $10 \mu \mathrm{g} / \mathrm{mL}$ of exposure concentration, more than $80 \%$ of the larvae were alive with the formulation while only $10 \%$ survived with the compound alone, which accounts for a major difference in survivability. All the population died at an exposure concentration of $15 \mu \mathrm{g} / \mathrm{mL}$, which confirms the lethality of this dose, as previously highlighted [15]. Even if the survival rate was improved with the formulation, morphological alterations, such as the disappearance of somite, necrosis in the tail, smaller size, cardiac toxicity, and abnormal movements of the larvae, once outside the chorion, were observed by binocular microscopy in both populations, at the same degree.

In this study, a targeted nanovectorization approach based on the results of Marques et al. [10] was tested for the administration of a natural antimalarial cytotoxic compound, poupartone B. The results show a decrease of toxicity and an improvement in effectiveness. The RSA $\mathrm{R}_{0-3 \mathrm{~h}}$, which is able to predict the potency of compounds against artemisinin-resistant parasites in malaria patients [24], demonstrated the potent activity of the heparin-targeted liposomes towards an artemisinin-resistant isolate compared to poupartone B alone. Furthermore, it confirmed that this formulation was able to kill resistant parasites, even with a short contact time. These results pave the way for further investigations on liposome formulation applied to alkyl cyclohexenone derivatives in the context of the DHA partial resistance observed in Asia. Cytotoxicity tests confirmed the decrease of toxicity by the formulation in both HeLa cells in vitro and in the zebrafish embryos model. Liposomes had already demonstrated their potential to decreased 

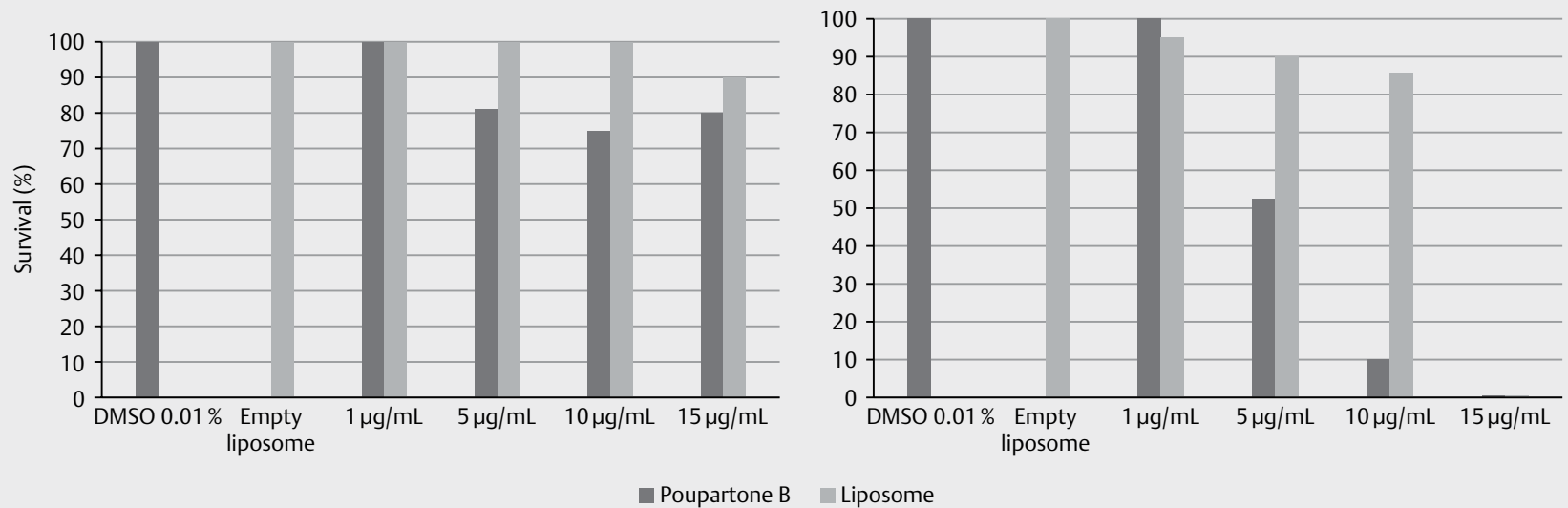

- Fig. 3 Survival (\%) of the zebrafish at 48 and $72 \mathrm{~h}$ exposure to the control (DMSO $0.01 \%$ ), liposomes containing heparin without poupartone B (empty liposome), a concentration range $(1-15 \mu \mathrm{g} / \mathrm{mL})$ of poupartone $B(1-15 \mu \mathrm{g} / \mathrm{mL})$, and liposomes containing the same quantity of poupartone B with heparin $(1-15 \mu \mathrm{g} / \mathrm{mL})$.

toxicity and improve effectiveness, and heparin has been highlighted for its ability to target iRBCs. This study contributes to highlighting the benefit of the combination of these strategies in terms of activity, especially against partially resistant $P$. falciparum strains. These approaches could represent an important advantage since the emergence of artemisinin resistance has become a major public health problem. This work also emphasizes the interest of an understudied class of natural compounds, the alkyl cyclohexanone derivatives, as potential bioactive substances. Objectively, even if poupartone $B$ is too toxic to be a good candidate for becoming an antimalarial drug, this class of compound should be investigated in more depth, since it isn't clear the mechanism of action through which the compounds exert both antiplasmodial activity and toxicity. At this moment, the structure-activity relationship has not been not clearly established. However, some hypotheses can be proposed considering the data present in the literature. It seems that this bioactive class of compounds frequently presents a ketone function $[16,18,19,26]$, and the toxicity appears to be related to the number of oxygen atoms. Some compounds of this group that demonstrated high bioactivities, without in vitro toxicity, contain less oxygen atoms than the others $[26,27]$. Thus, poupartone $B$ can be a good precursor for semisynthetic compounds with higher therapeutic potential and selectivity.

The discussed data indicates that a heparin-targeted nanovectorization system is efficient and could be successfully applied against artemisinin-resistant $P$. falciparum. Furthermore, the erythrocytic stage of malaria was the exclusive phase investigated. Other studies have demonstrated that heparin can also target different $P$. falciparum stages, such as the sexual stage in mosquitoes. This might pave the way for multiple approaches to proceed with these studies.

Nanotechnology will be a key player in the fight against the occurrence of drugs resistance, especially in the field of malaria, where new treatments are urgently needed.

\section{Materials and Methods}

\section{General experimental procedures}

Except where otherwise indicated, all lipid materials were purchased from Avanti Polar Lipids and all reagents were purchased from Sigma-Aldrich. Poupartone B was isolated from the leaves of male plants of $P$. borbonica, as previously described by our team (purity $>98 \%$ according to HPLC analysis) [15]. This anacardiaceae was collected in Langevin, Reunion Island, in June 2018 and identified by Hermann Thomas (Parc National de La Réunion). Voucher specimens (no. RUN 028F, TCN-P022F) were deposited in the Herbarium of the University of Reunion Island.

\section{Liposomes preparation}

Liposomes were prepared by the lipid film hydration method [28]. Different formulations (with and without bounded heparin) were performed based on the protocol described by Marques et al. [10] Briefly, lipids ( $N$-[1-(2,3-dioleoyloxy)propyl]-N,N,N-trimethylammonium methyl-sulfate, DOTAP (4\% molar), 1,2-dioleoyl-sn-glycero-3-phosphocholine, DOPC (76\% molar), and cholesterol $(20 \%$ molar) (ovine wool, > 98\%) were dissolved with poupartone B in chloroform ( $20 \mathrm{mM}$ total lipids with a poupartone $B$ concentration of $2.6 \mathrm{mM}$ ). The organic solvent was removed by rotary evaporation under reduced pressure at $37^{\circ} \mathrm{C}$ to yield a lipid film. The film was hydrated with $1.0 \mathrm{~mL} \mathrm{PBS} \mathrm{(pH} \mathrm{7.4).} \mathrm{Liposomes} \mathrm{were} \mathrm{formed} \mathrm{by}$ vortexing and downsized by extrusion through polycarbonate membranes ( 5 times on $400 \mathrm{~nm}, 3$ times on $200 \mathrm{~nm}$, and 3 times on $100 \mathrm{~nm}$ ). Liposomes were purified 3 times by ultracentrifugation at $35000 \mathrm{rpm}$ at $4^{\circ} \mathrm{C}$ during $2 \mathrm{~h}$ by cycle (Beckman Coulter, Optima L-90K). Heparin was electrostatically bound to cationic liposomes by the addition of proportional $100-150 \mu \mathrm{g}$ heparin/mL PBS for $20 \mathrm{mM}$ of lipid liposome preparation containing $4 \%$ DOTAP. The unbound heparin was removed by ultracentrifugation with the same conditions described for the purification and all supernatants were collected for NMR quantification. Liposomes size, PDI, and zeta potential were obtained by a dynamic light scattering technic 
using Malvern Zetasizer (Nano ZS; Malvern Instruments). Encapsulated poupartone B was quantified by an HPLC-DAD method. Except where otherwise indicated, the term "formulation" is used to designate the liposomes containing poupartone $B$ and bounded heparin.

\section{Poupartone B quantification}

Analytical HPLC was carried out on an Agilent 1100 Series at a flow rate of $1 \mathrm{~mL} / \mathrm{min}$. An RP select B LiChrospher 60 (250 × $4.6 \mathrm{~mm})$ column was chosen. A mobile phase composed of formic acid $0.1 \%$ in water and methanol was used in a gradient elution (40:60 to $0: 100 \mathrm{v} / \mathrm{v}$ in $30 \mathrm{~min})$. The UV-Vis detector was set at $254 \mathrm{~nm}$. The HPLC-DAD method was validated. The following criteria were investigated: linearity, trueness, precision, accuracy, LOD, and LOQ. Pre-validation of the method was performed on two series with three independent replicates at three concentrations (20,50, and $100 \mu \mathrm{g}$ in the presence of $20 \mathrm{mM}$ lipids such as in the liposome preparation) over a period of 2 days. Data processing was performed with Enoval 4.1 software.

When the formulation was analyzed, a calibration curve was performed for each quantification. Liposomes were diluted 10 times in $\mathrm{MeOH}$ and destroyed by ultra-sonication before being injected into HPLC for poupartone B quantification.

\section{Heparin NMR quantification}

${ }^{1} \mathrm{H}$ NMR spectra were recorded in $\mathrm{D}_{2} \mathrm{O}$ on a Bruker Avance spectrometer operating at $500.13 \mathrm{MHz}$ equipped with a cryoprobe. Maleic acid (purity > 99\%; Sigma-Aldrich) was used as an internal standard for 1D experiment quantification. All spectra were calibrated with internal sodium 3-trimethylsilyl-2,2,3,3-d4-propionate at the $0.00 \mathrm{ppm}$ chemical shift. All the supernatants collected during the liposome preparation were gathered and lyophilized. The lyophilizate was dissolved in $\mathrm{D}_{2} \mathrm{O}$, and $700 \mu \mathrm{L}$ of this solution were taken to quantify the heparin that had not bound to the liposomes. The amount of heparin bound to the liposomes was deduced by the difference between what was initially introduced and what was not bound.

\section{In vitro antiplasmodial activities}

Continuous in vitro cultures of asexual erythrocyte stages of $P$. falciparum, chloroquine-sensitive strain 3D7 (originally isolated from a patient living near Schipol airport in the Netherlands) [29], and artemisinin partially resistant strain IPC 3445 (originally isolated from a patient in western Cambodia in 2010) [30] were maintained following the procedure of Trager and Jensen [31]. Strains were obtained from ATCC, Bei Resources. The host cells were human red blood cells $(A+)$. The culture medium comprised RPMI 1640 (Gibco, Fisher Scientific) containing $\mathrm{NaHCO}_{3}(32 \mathrm{mM})$, HEPES (25 mM), and $\mathrm{L}$-glutamine. The medium was supplemented with $1.76 \mathrm{~g} / \mathrm{L}$ of glucose (Sigma-Aldrich), $44 \mathrm{mg} / \mathrm{mL}$ of hypoxanthine (Sigma-Aldrich), $100 \mathrm{mg} / \mathrm{L}$ of gentamycin (Gibco, Fisher Scientific), and 10\% human pooled serum $(A+)$, as previously described $[6,15]$.

Liposome solutions were directly diluted in the medium; each test sample was applied in a series of eight 2 -fold dilutions in a 96-well plate and tested in triplicate (concentration tested was calculated in $\mu \mathrm{g} / \mathrm{mL}$ of poupartone B). The parasitemia was $2 \%$, and the hematocrit was $1 \%$, as previously described [32]. Parasite growth was estimated after $48 \mathrm{~h}$ incubation by the determination of lactate dehydrogenase activity, according to the methods described by Makler et al. [33]. Artemisinin (purity > 98\%; Sigma-Aldrich) at an initial concentration of $100 \mathrm{ng} / \mathrm{mL}$ was used as positive control in all experiments. $I C_{50}$ (half-maximal inhibitory concentration) values were calculated from sigmoidal curves.

\section{Ring-stage survival assay $(0-3 \mathrm{~h})$}

Ring-stage survival assays were performed on artemisinin partially resistant strain IPC 3445 as previously described by Witkowski et al. [25] and Baumgärtner et al. [24].

Briefly, 0-3 h post-invasion ring stages were adjusted to $2 \%$ hematocrit and $1 \%$ parasitemia. Of this solution, $900 \mu \mathrm{L}$ were added to $100 \mu \mathrm{L}$ of solutions containing DHA (700 nM) (purity > 97\%; Sigma-Aldrich), poupartone $B(2.6 \mu \mathrm{M})$, or liposome formulation (2.6 $\mu \mathrm{M}$ of poupartone $\mathrm{B})$. Tests were performed in 48 -well plates and exposed for $6 \mathrm{~h}$. Afterwards, cultures were transferred to $15 \mathrm{~mL}$ tubes and were centrifuged at $800 \mathrm{~g}$ for $5 \mathrm{~min}$. The blood pellets were dispersed in medium $(10 \mathrm{~mL})$ in a cleaning step. After removing the drug, the red blood cells were dispersed with $1 \mathrm{~mL}$ of culture media. They were transferred to new wells for a 66-h incubation period. The survival percentage was established by comparing the number of viable iRBCs after explosion in thin blood smears to that of the drug-free DMSO incubation.

\section{In vitro cytotoxic activity}

Assays were performed on HeLa cells to evaluate the cytotoxicity potential of the formulation and the compound alone. Compounds were tested in 96-well microplates using the tetrazolium salt WST-1 (Roche Diagnostics Belgium) colorimetric assay based on the cleavage of the reagent by mitochondrial succinate-tetrazolium reductase in living cells. Tests were performed as previously described [15]. Briefly, cells were seeded 6000 per well in $200 \mu \mathrm{L}$ of medium supplemented with adequate concentrations of the tested drugs. After $48 \mathrm{~h}$ of incubation, $10 \mu \mathrm{L}$ of WST- 1 were added to each well. After 30 min at $37^{\circ} \mathrm{C}$, the plates were shaken, and absorbance values were recorded at $450 \mathrm{~nm}$. The absorbance values were expressed in percentage terms compared to untreated control cells. $I C_{50}$ values were calculated from graphs. The HeLa cells were obtained from the Laboratory of Medical Chemistry, GIGA, ULg.

\section{In vitro hemolytic activity}

A red blood cell suspension $[A+, 10 \%$ in PBS ( $v / v)$ ] was incubated with poupartone $B$ and liposomal formulation in triplicate. The final concentration was $5 \mu \mathrm{g} / \mathrm{mL}$ for poupartone $B$ (with and without formulation) and the corresponding formulation without the active compound. After agitation at room temperature for $1 \mathrm{~h}$, the tubes were centrifuged for $5 \mathrm{~min}$ at $2000 \mathrm{rpm}$, and $150 \mu \mathrm{L}$ of each supernatant were transferred to a 96 -microwell plate to measure the absorbance (OD) at $550 \mathrm{~nm}$ with a microplate reader. The positive control was Triton X-100 1\% (v/v) and PBS as the negative control. The percentage of red blood cell lysis $(H)$ was calculated as follows: $\mathrm{H}=($ OD550 nm sample - OD550 nm PBS)/(OD550 nm Triton $\mathrm{X}-1001 \%(\mathrm{v} / \mathrm{v})$ - OD550 nm PBS), as previously described [15]. 


\section{Selectivity index}

The selectivity index was obtained as the ratio of $\mathrm{IC}_{50}$ between the cytotoxic activity on HeLa cells and 3D7 or IPC 3445 parasitic activities, respectively.

\section{Zebrafish embryos acute toxicity test}

Adult zebrafish (Danio rerio) were maintained while fulfilling the criteria of the Ethical Committee for the Use of Laboratory Animals at the University of Liège. They were maintained at $28^{\circ} \mathrm{C}$ on a $14-\mathrm{h}$ day/10-h night period, and fertilized eggs were collected, washed with sterile water, and placed in petri dishes. Embryos were collected, and their chorions were not removed. Previously, in another study, our team determined the $\mathrm{LC}_{50}$ (half-maximal lethal exposure concentration) for poupartones [15]. Consequently, the narrower geometric series was performed without first carrying out the logarithmic concentrations series test [34] to avoid wasting fish uselessly.

Poupartone B was dissolved in DMSO solution and was diluted with the medium used for the zebrafish. The exposure concentrations of poupartone B were between 1 and $15 \mu \mathrm{g} / \mathrm{mL}$, both individually and in the formulation, with full knowledge from previous studies that at a concentration of $15 \mu \mathrm{g} / \mathrm{mL}$ of the compound is completely lethal in the zebrafish model [15]. The DMSO's final highest concentration was $0.4 \%$. The liposome formulations were directly dissolved in the medium used for zebrafish. Twenty embryos were used per condition in a 6 -well plate. Each well contained $5 \mathrm{~mL}$ of the treatment dose, which was replaced once daily for 3 days. The embryos were observed each day until $72 \mathrm{~h}$ post-fertilization. Wells with 20 embryos were used as the control for the solvent (DMSO, $0.4 \%$ ), the formulation (liposome + heparin), and poupartone B at $15 \mu \mathrm{g} / \mathrm{mL}$.

\section{Statistical analysis}

Statistical significance between the compound and the formulation was set at $p<0.05$ and analyzed with Student's t-test in GraphPad Prism.

\section{Acknowledgments}

The authors wish to thank P. Desdemoustier for her essential support, and D. Étienne and N. Bulté for their technical assistance. E. Boyer, T. Hermann, and M. Felicite from Reunion Island are acknowledged for the plant collection. The following reagents were obtained through BEI Resources Repository, NIAID, NIH: P. falciparum, strain 3D7, and MRA-102 contributed by Daniel J. Carucci.

\section{Conflict of Interest}

The authors declare that they have no conflict of interest.

\section{References}

[1] D'Alessandro $\mathrm{U}$, Buttiens $\mathrm{H}$. History and importance of antimalarial drug resistance. Trop Med Int Heal 2001; 6: 845-848
[2] World Health Organization. World malaria report 2016. WHO, 186. Available at: http://www.who.int/malaria/publications/world-malariareport-2016/report/en/, Accessed 16 March 2020

[3] Tilley L, Straimer J, Gnädig NF, Ralph SA, Fidock DA. Artemisinin action and resistance in Plasmodium falciparum. Trends Parasitol 2016; 32: 682-696

[4] Witkowski B, Lelièvre J, Barragán MJL, Laurent V, Su XZ, Berry A, Benoit-Vical F. Increased tolerance to artemisinin in Plasmodium falciparum is mediated by a quiescence mechanism. Antimicrob Agents Chemother 2010; 54: 1872-1877

[5] Newman DJ, Cragg GM. Natural products as sources of new drugs from 1981 to 2014. J Nat Prod 2016; 79: 629-661

[6] Bordignon A, Frédérich M, Ledoux A, Campos PE, Clerc P, Hermann T, Quetin-Leclercq J, Cieckiewicz E. In vitro antiplasmodial and cytotoxic activities of sesquiterpene lactones from Vernonia fimbrillifera Less. (Asteraceae). Nat Prod Res 2017; 32: 1463-1466

[7] Helms G, Dasanna AK, Schwarz US, Lanzer M. Modeling cytoadhesion of Plasmodium falciparum-infected erythrocytes and leukocytes-common principles and distinctive features. FEBS Lett 2016; 590: 1955-1971

[8] Juillerat A, Igonet S, Vigan-Womas I, Guillotte M, Gangnard S, Faure G, Baron B, Raynal B, Mercereau-Puijalon O, Bentley GA. Biochemical and biophysical characterisation of DBL1 11 -varO, the rosetting domain of PfEMP1 from the VarO line of Plasmodium falciparum. Mol Biochem Parasitol 2010; 170: 84-92

[9] Regev-Rudzki N, Wilson DW, Carvalho TG, Sisquella X, Coleman BM, Rug M, Bursac D, Angrisano F, Gee M, Hill AF, Baum J, Cowman AF. Cell-cell communication between malaria-infected red blood cells via exosome-like vesicles. Cell 2013; 153: 1120-1133

[10] Marques J, Moles E, Urbán P, Prohens R, Busquets MA, Sevrin C, Grandfils C, Fernández-Busquets X. Application of heparin as a dual agent with antimalarial and liposome targeting activities toward Plasmodium-infected red blood cells. Nanomedicine 2014; 10: 1719-1728

[11] Rathore D, McCutchan TF. Heparin can regulate the binding of Plasmodium falciparum circumsporozoite protein. Mol Biochem Parasitol 2000; 108: 253-256

[12] Ismail M, Ling L, Du Y, Yao C, Li X. Liposomes of dimeric artesunate phospholipid: A combination of dimerization and self-assembly to combat malaria. Biomaterials 2018; 163: 76-87

[13] Isacchi B, Arrigucci S, La Marca G, Bergonzi MC, Vannucchi MG, Novelli A, Bilia AR. Conventional and long-circulating liposomes of artemisinin: preparation, characterization, and pharmacokinetic profile in mice. J Liposome Res 2011; 21: 237-244

[14] Aditya NP, Vathsala PG, Vieira V, Murthy RSR, Souto EB. Advances in nanomedicines for malaria treatment. Adv Colloid Interface Sci 2013; 201-202: 1-17

[15] Ledoux A, St-Gelais A, Cieckiewicz E, Jansen O, Bordignon A, Illien B, Di Giovanni N, Marvilliers A, Hoareau F, Pendeville H, Quetin-Leclercq J, Frédérich $\mathrm{M}$. Antimalarial activities of alkyl cyclohexenone derivatives isolated from the leaves of Poupartia borbonica. J Nat Prod 2017; 80: 1750-1757

[16] Otto A, Porzel A, Schmidt ], Brandt W, Wessjohann L, Arnold N. Structure and absolute configuration of pseudohygrophorones $A^{12}$ and $\mathrm{B}^{12}$, alkyl cyclohexenone derivatives from Hygrophorus abieticola (Basidiomycetes). J Nat Prod 2016; 79: 74-80

[17] Roumy V, Fabre N, Portet B, Bourdy G, Acebey L, Vigor C, Valentin A, Moulis $C$. Four anti-protozoal and anti-bacterial compounds from Tapirira guianensis. Phytochemistry 2009; 70: 305-311

[18] David JM, Chavez JP, Chai HB, Pezzuto JM, Cordell GA. New cytotoxic compounds from Tapirira guianensis. J Nat Prod 1998; 61: 287-289 
[19] Correia SD], David JM, David JP, Chai HB, Pezzuto JM, Cordell GA. Alkyl phenols and derivatives from Tapirira obtusa. Phytochemistry 2001; 56: 781-784

[20] Bozzuto G, Molinari A. Liposomes as nanomedical devices. Int ] Nanomedicine 2015; 10: 975-999

[21] Kang JH, Jang WY, Ko YT. The effect of surface charges on the cellular uptake of liposomes investigated by live cell imaging. Pharm Res 2017; 34: 704-717

[22] Naveen P, Lingaraju HB, Deepak M, Medhini B, Prasad KS. Method development and validation for the determination of caffeine: An alkaloid from Coffea arabica by high-performance liquid chromatography method. Pharmacognosy Res 2018; 10: 88-91

[23] Whiteman P. The quantitative measurement of Alcian Blue-glycosaminoglycan complexes. Biochem J 1973; 131: 343-350

[24] Baumgärtner F, Jourdan J, Scheurer C, Blasco B, Campo B, Mäser P, Wittlin $\mathrm{S}$. In vitro activity of anti-malarial ozonides against an artemisinin-resistant isolate. Malar J 2017; 16: 45

[25] Witkowski B, Khim N, Chim P, Kim S, Ke S, Kloeung N, Chy S, Duong S, Leang R, Ringwald P, Dondorp AM, Tripura R, Benoit-Vical F, Berry A, Gorgette O, Ariey F, Barale JC, Mercereau-Puijalon O, Menard D. Reduced artemisinin susceptibility of Plasmodium falciparum ring stages in western Cambodia. Antimicrob Agents Chemother 2013; 57 : 914-923

[26] Yaouba S, Koch A, Guantai EM, Derese S, Irungu B, Heydenreich M, Yenesew A. Alkenyl cyclohexanone derivatives from Lannea rivae and Lannea schweinfurthii. Phytochem Lett 2017; 23: 141-148
[27] Okoth DA, Akala HM, Johnson JD, Koorbanally NA. Alkyl phenols, alkenyl cyclohexenones and other phytochemical constituents from Lannea rivae (chiov) Sacleux (Anacardiaceae) and their bioactivity. Med Chem Res 2016; 25: 690-703

[28] MacDonald RC, MacDonald RI, Menco BP, Takeshita K, Subbarao NK, Hu LR. Small-volume extrusion apparatus for preparation of large, unilamellar vesicles. Biochim Biophys Acta 1991; 1061: 297-303

[29] BEI Resources, BEl Reagent Search. Available at https://www. beiresources.org/Catalog/BEIParasiticProtozoa/MRA-102.aspx, Accessed 16 March 2020

[30] BEl Resources, BEl Reagent Search. Available from https://www. beiresources.org/Catalog/BEIParasiticProtozoa/MRA-1236.aspx, Accessed 16 March 2020

[31] Trager W, Jensen JB. Human malaria parasites in continuous culture. Science 1976; 193: 673-675

[32] Jansen O, Angenot L, Tits M, Nicolas JP, De Mol P, Nikiéma JB, Frédérich M. Evaluation of 13 selected medicinal plants from Burkina Faso for their antiplasmodial properties. J Ethnopharmacol 2010; 130: 143-150

[33] Makler MT, Ries JM, Williams JA, Bancroft JE, Piper RC, Gibbins BL, Hinrichs DJ. Parasite lactate dehydrogenase as an assay for Plasmodium falciparum drug sensitivity. Am J Trop Med Hyg 1993; 48: 739-741

[34] Ali S, Mil HG] Van, Richardson MK. Large-scale assessment of the zebrafish embryo as a possible predictive model in toxicity testing. PLoS One 2011; 6: e21076 